\title{
Electrochemical investigation of NO at single-wall carbon nanotubes modified electrodes
}

\author{
TINGLIANG XIA ${ }^{1,2}$, HONGMEI BI ${ }^{1,2}$ and KEYING SHI ${ }^{1,2, *}$ \\ ${ }^{1}$ Key Laboratory of Functional Inorganic Material Chemistry, Ministry of Education, Harbin, \\ China 150080 \\ ${ }^{2}$ Key Physical Chemistry Laboratory, School of Chemistry and Materials Science, \\ Heilongjiang University, Harbin, China 150080 \\ e-mail: shikeying2008@yahoo.cn
}

MS received 3 June 2009; revised 22 October 2009; accepted 5 November 2009

\begin{abstract}
The NO electro-oxidation was investigated at various single-wall carbon nanotubes (SWCNTs) modified electrodes by cyclic voltammetry (CV) and electrochemical impedance spectroscopy (EIS). Compared with the glassy carbon electrode, the SWCNTs modified electrodes possess higher electro-catalytic activity to NO electro-oxidation. CV results indicate that the peak current density of NO electro-oxidation at the SWCNT-COOH (SWCNTs with carboxyl groups) modified electrode is the highest and the peak potential is the most negative among the four kinds of electrodes. EIS indicates that the charge transfer resistance of NO electro-oxidation at the SWCNT-COOH modified electrode is the least. The determined factors (charge transfer and mass transfer of diffusion) of NO electro-oxidation are different in varied potential region. The mechanism of NO electro-oxidation reaction at the SWCNTs modified electrodes is also discussed.
\end{abstract}

Keywords. SWCNTs modified electrode; NO; electro-oxidation.

\section{Introduction}

The unique properties of carbon nanotubes (CNTs), including high surface area, high electrical conductivity, nanometer size, hollow geometric structure and so on, have been widely studied by scientists in various disciplines. ${ }^{1,2}$ CNTs have been extensively developed for many special fields, such as optical or electronic devices, drug delivery systems, chemical or biological sensors and catalysts, etc. ${ }^{3-6}$ Due to their gas adsorption and storage ability, CNTs are often used as the electrode material for gas sensors. Gases such as $\mathrm{NO}_{2}, \mathrm{NH}_{3}, \mathrm{CH}_{4}, \mathrm{O}_{2}$ have organic and inorganic vapors have been successfully detected by SWCNTs-based sensors. ${ }^{7-15}$

Nitric oxide (NO) is one of the pollutants in atmosphere and can be easily oxidized by $\mathrm{O}_{2}$ which makes it hard to be detected. Several methods, include chemiluminescene, photoluminescene, thermal conductivity and semiconducting electrical conductivity, ${ }^{16-18}$ have been reported on NO detection. Conductive gas sensors based on CNTs have

\footnotetext{
*For correspondence
}

also been reported. ${ }^{19-22}$ Jani et $a l^{23}$ reported the preparation of a conductive NO gas sensor with carboxyl functionalized SWCNTs and MWCNTs. Recently, NO electro-oxidation has been investigated based on the modified electrodes with porphyrin, ${ }^{24}$ phthalocyanine ${ }^{25,26}$ and nanomaterials. ${ }^{27-29}$ However, low sensitivity and poor selectivity have limited their further application. Thus, there is a need to develop a new electrode material to optimize the electrochemical properties for NO detection. Previous studies revealed that CNTs modified electrodes have excellent electrochemical properties, such as a wide potential window, small background current and high electrocatalytic activities, which are superior to those of traditional carbon electrodes ${ }^{30-35} \mathrm{At}$ present, the electro-oxidation method has been successfully applied to some gases, such as, $\mathrm{CO}^{36}$ $\mathrm{CH}_{4}{ }^{37}$ However, little has been reported about NO electrochemical sensors prepared with CNTs. Fu et $a l^{38}$ used SWCNTs network devices to detect NO, but the mechanism of the interaction between NO and metal/CNTs junctions has not been fully disscussed. Li et $a l^{39}$ studied NO electro-oxidation at a SWCNTs/room temperature ionic liquid (RTIL) gel 
microelectrode and the experimental results revealed that the gel microelectrode had great potential for application in a NO sensor, but some neutral biological species still need to be further investigated for their interferences.

In this paper, several types of functionalized SWCNTs were modified on the GC electrode. The electro-catalytic activity of these electrodes was investigated by cyclic voltammetry (CV). Electrochemical impedance spectroscopy (EIS) and ion chromatography (IC) were carried out in order to discuss the mechanism of NO electro-oxidation.

\section{Experimental}

\subsection{Reagents and instruments}

The SWCNTs was from Chengdu Organic Chemicals Co. Ltd., with the diameter range from 1 to $2 \mathrm{~nm}$ and the length range from 5 to $30 \mu \mathrm{m}$, the purity was higher than $90 \%$. All other chemicals used were of analytical-grade without further purification. All solutions were prepared by deioned and doubly distilled water. All electrochemical experiments were carried out at ambient temperature.

\subsection{SWCNTs treated by different chemical methods}

$\mathrm{KOH}$ was mixed with the SWCNTs in an agate mortar with the mass ratio $10: 1$ of $\mathrm{KOH}$ to the SWCNTs, and grounded well. The mixture was heated from ambient temperature to $1073 \mathrm{~K}$ at the raising speed of $10 \mathrm{~K} \mathrm{~min}^{-1}$ in high purity nitrogen $\left(\mathrm{N}_{2}, 99.999 \%\right)$ flow $\left(420 \mathrm{~mL} \mathrm{~min}^{-1}\right)$, keeping for $2 \mathrm{~h}$ at $1073 \mathrm{~K}$, and then cooled down to ambient temperature. The treated solid was washed with water until the $\mathrm{pH} 7 \cdot 0$ and then dried at $383 \mathrm{~K}$ for $48 \mathrm{~h}$. The sample was denoted as SWCNT-OH. The SWCNT-OH was treated by the mixed acids, ${ }^{40}$ after treatment the sample was denoted as the SWCNT-COOH.

\subsection{Electrochemical experiments}

Glassy carbon electrode (GC) with diameter $4 \mathrm{~mm}$ was polished before each experiment, then sonicated in ethanol, acetone and water respectively and dried at ambient temperature. Three types of SWCNTs were used to modify the GC electrode. They were pure SWCNTs, SWCNT-OH and SWCNT-COOH $0.25 \mathrm{mg}$ each SWCNTs was dispersed in $10 \mathrm{~mL}$ acetone accompanied by ultrasonic process to get a suspension. $10 \mu \mathrm{L}$ suspension was dropped on the surface of the GC electrode, and the solvent was gradually evaporated under an IR lamp. Then three kinds of modified electrode were obtained.

Electrochemical experiments were performed in an electrolytic cell with three electrodes. The GC electrode or various SWCNTs modified electrodes was used as a working electrode, a platinum sheet was served as an auxiliary electrode, and an $\mathrm{Ag} /$ $\mathrm{AgCl}$ electrode was used as a reference electrode. $0.1 \mathrm{~mol} \mathrm{~L}^{-1} \quad \mathrm{KH}_{2} \mathrm{PO}_{4}-\mathrm{NaOH}$ buffer solution (PBS) was taken as a blank solution, the $\mathrm{pH}$ value was $6 \cdot 8$. The solution was bubbled by high purity $\mathrm{N}_{2}$ (99.999\%), for $30 \mathrm{~min}$ to remove oxygen, and then the solution was bubbled with pure NO (99.999\%) for $30 \mathrm{~min}$ to prepare a NO saturated solution. The CV was measured by LK98IIB electrochemical analyzer (Lanlik Instrument Co. Ltd., Tianjin, China), the scanning speed was $50 \mathrm{mV} \mathrm{s}^{-1}$, and the range of potential sweep was $300-1400 \mathrm{mV}$. The EIS was measured by IM6e impedance measurement unit (ZAHNER Elektrik, Germany). The AC voltage amplitude was $10 \mathrm{mV}$, the frequency range was from $10 \mathrm{mHz}$ to $100 \mathrm{kHz}$, and the data were processed with Zview2 software.

\subsection{Characterization}

FTIR Spectrometer (Perkin Elmer Spectrum one) was used to detect IR spectra of various functionalized SWCNTs. LC-20A ion chromatograph (Shimadzu, Japan), which consisted of a Model LP-20ADsp liquid delivery pump, a conductivity detector Model CDD-10Avp, an autosample injector Model SIL20A, a Model CTO-20AC column oven and a system controller Model SCL-10Avp, was applied to detect $\mathrm{NO}_{2}^{-}$and $\mathrm{NO}_{3}^{-}$concentration of electrolyte solution before and after reaction.

\section{Results and discussion}

\subsection{FTIR characterization}

Figure 1 shows IR spectra of the SWCNTs, SWCNT-OH and SWCNT-COOH samples. It can be seen that all curves have the same peak at $1557 \mathrm{~cm}^{-1}$, which is attributed to $\mathrm{C}-\mathrm{C}$ stretching vibration in SWCNTs. The absorption peak at $3424 \mathrm{~cm}^{-1}$ of the SWCNT-OH sample (figure $1 \mathrm{~b}$ ) is assigned to $\mathrm{O}-\mathrm{H}$ vibration, ${ }^{41}$ which is more intense than that of pure SWCNTs (figure 1a); the result 
shows that after alkali treatment there are a large number of hydroxyl groups on the surface of the SWCNTs. An absorption peak at $1705 \mathrm{~cm}^{-1}$ of the SWCNT-COOH sample (figure 1c) is assigned to stretching vibration of carbonyl in carboxyl groups. ${ }^{42}$ The broad absorption peak about $1385 \mathrm{~cm}^{-1}$ is due to the stretching vibration of $-\mathrm{OH}$ in carboxyl group, the results have further confirmed that after acid treatment there are a large number of carboxyl groups on the surface of the SWCNT-COOH. The carboxyl content of SWCNTs obtained in the paper is about $5 \cdot 3 \%$ by acid-base titration.

\subsection{NO electro-oxidation at various functionalized SWCNTs modified electrode}

Figure 2 shows cyclic voltammograms at the GC electrode and various SWCNTs modified electrodes in the PBS saturated with NO. The peak current density of various SWCNTs modified electrodes increases significantly compared with the GC electrode. The peak potentials have negative shifts in some degree. The peak current reflects the rate of the electrode reaction, and the peak potential reflects the activation energy of the electrode reaction, therefore, the experimental results show that SWCNTs modified electrodes have higher reaction rate and lower activation energy for NO electrooxidation reaction compared with the $\mathrm{GC}$ electrode (figure 2). The SWCNTs modified electrodes exhibits better electro-catalytic activity to NO electrooxidation than the GC electrode.

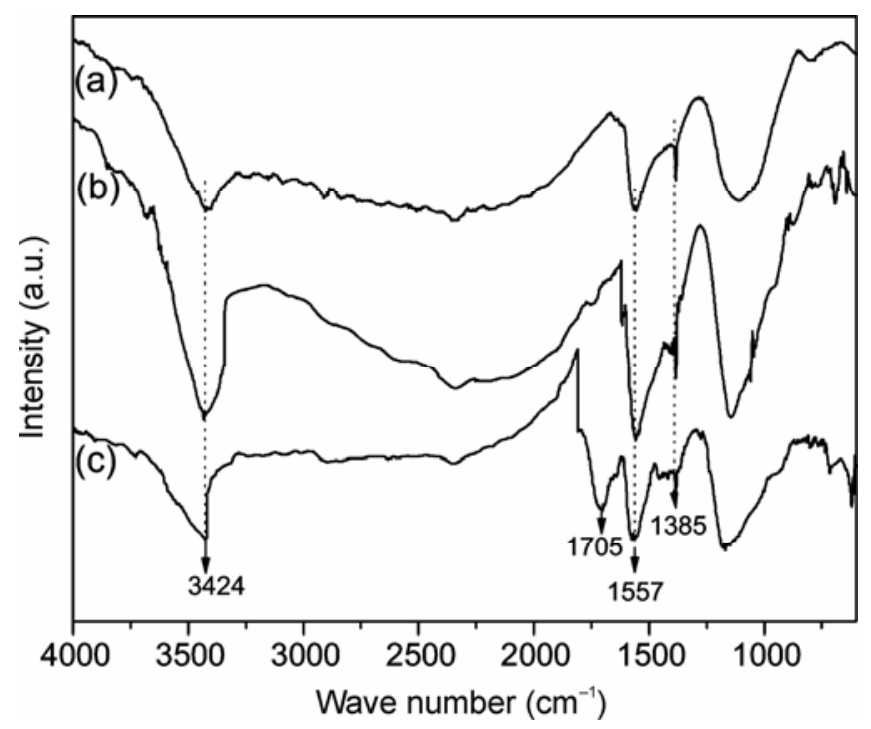

Figure 1. IR spectra of various SWCNTs: SWCNTs, (b) SWCNT-OH, (c) SWCNT-COOH.
It can be seen from figure 2 that the SWCNT$\mathrm{COOH}$ modified electrode has the highest peak current density, and the most negative peak potentials
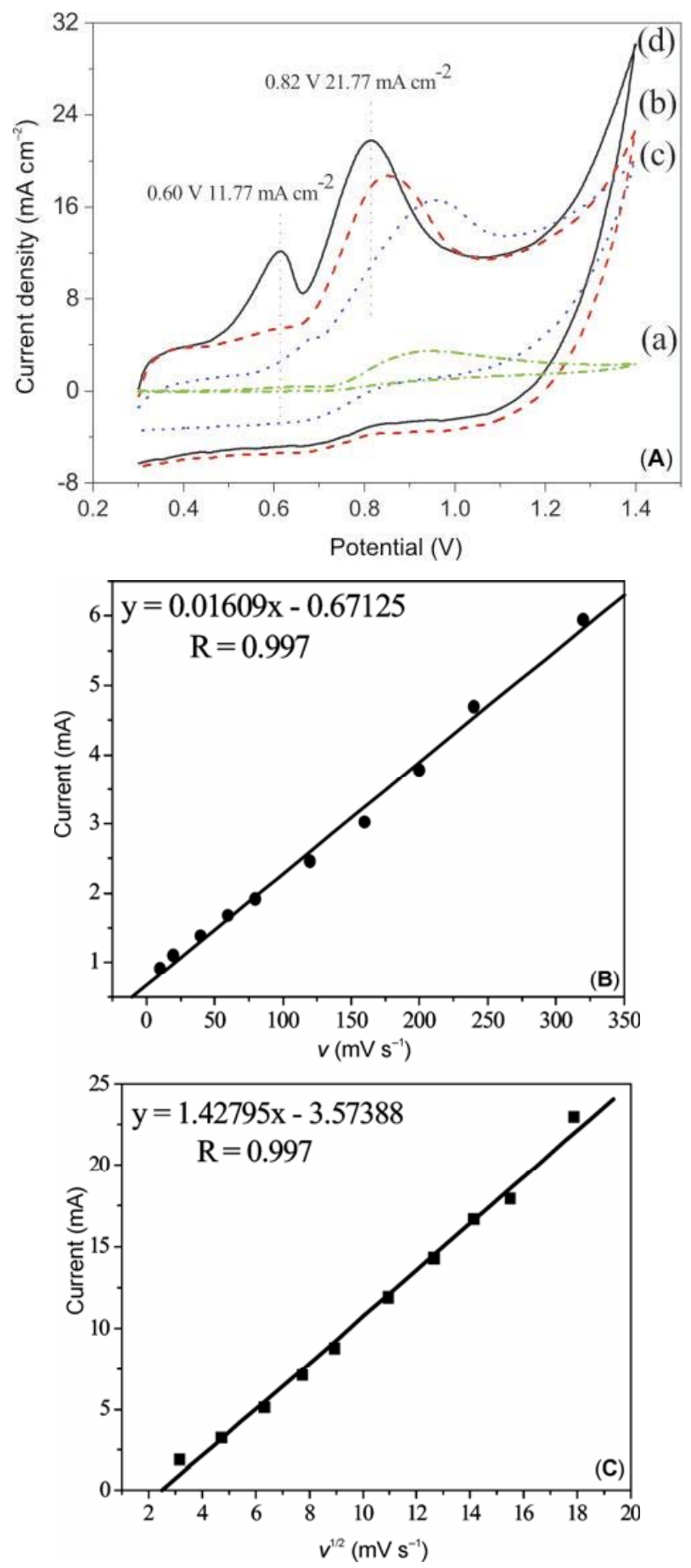

Figure 2. (A) Cyclic voltammograms at various electrodes in the PBS saturated with NO: (a) GC, (b) SWCNTs, (c) SWCNT-OH, (d) SWCNT-COOH (The scan rate is $50 \mathrm{mV} \mathrm{s}^{-1}$ ). (B) Dependency of peak $\mathrm{P}_{1}$ current on the corresponding scan rate in the range from 10 to $320 \mathrm{mV} \mathrm{s}^{-1}$. (C) Dependency of peak $\mathrm{P}_{2}$ currents on the corresponding square root of the scan rate in the range from 10 to $320 \mathrm{mV} \mathrm{s}^{-1}$. 
among them. There are two oxidation peaks in figure $2 \mathrm{~d}$; the first peak potential emerges at about $0.60 \mathrm{~V}$, the second peak potential is $0.82 \mathrm{~V}$. The current density of the second peak is $21.77 \mathrm{~mA} \mathrm{~cm}^{-2}$, which is 1.2 times the value of the SWCNTs modified electrode $\left(17.77 \mathrm{~mA} \mathrm{~cm}^{-2}\right.$ at $\left.0.82 \mathrm{~V}\right), 2$ times the value of the SWCNT-OH modified electro de $\left(10.93 \mathrm{~mA} \mathrm{~cm}^{-2}\right.$ at $\left.0.82 \mathrm{~V}\right)$ and 11 times value of the bare GC electrode $\left(1.98 \mathrm{~mA} \mathrm{~cm}^{-2}\right.$ at $\left.0.82 \mathrm{~V}\right)$. The result indicated that SWCNT-COOH increases the electro-catalytic activity of SWCNTs to NO electro-oxidation.

The cyclic voltammograms at the SWCNT$\mathrm{COOH}$ modified electrode in the PBS saturated with NO exhibit two irreversible oxidation peaks, located at $0.60 \mathrm{~V}$ and $0.82 \mathrm{~V}$ (labelled as $\mathrm{P}_{1}$ and $\mathrm{P}_{2}$ ), respectively. Figure $2 \mathrm{~B}$ shows the dependency of $\mathrm{P}_{1}$ peak current on the potential scan rate, it can be seen that $P_{1}$ peak current depend linearly on the potential scan rate with a linear correlation coefficient of $0.997 ; \mathbf{P}_{1}$ peak corresponds to a surface-confined process and relates to the adsorption of reactants. Figure 2C shows the dependency of $\mathrm{P}_{2}$ peak current on the square root of the potential scan rate with a linear correlation coefficient of 0.997. Therefore, $\mathrm{P}_{2}$ peak corresponds to a diffusion-controlled process, and relates to the diffusion of reactants from the bulk solution to the electrode surface.

After the hydroxyl groups on the SWCNTs surface are replaced by the carboxyl groups, the lone electron pair of oxygen atom at carbonyl group in the carboxyl group forms a covalent adsorption with nitrogen atom of NO, which makes electron exchange of NO easier on the surface of SWCNTs. The NO adsorptive ability of the electrode is enhanced. Since the adsorption state of NO can be electro-oxidized in the lower potential, the first oxidation peak at the lower potential occurs.

The treatment of SWCNTs by $\mathrm{KOH}$ influences the NO adsorption of SWCNTs in two aspects. One is positive. With the increase of the specific surface area and the number of active sites on the SWCNTs surface, ${ }^{43,44}$ the NO adsorption of SWCNTs improved. The other is negative. Because of the steady covalent bond between oxygen and hydrogen in the introduced hydroxyl groups on the SWCNT$\mathrm{OH}$ surface, the oxygen atom in the hydroxyl groups can not adsorb NO molecules. The hydroxyl groups on the electrode surface blocks the charge transfer of NO electro-oxidation. This leads to the increase of the activation energy and reduction of the reaction rate. From the positive shift of the peak potential and the decrease of the peak current density (figure $2 \mathrm{c}$ compared with figure $2 \mathrm{~b}$ ), it can be concluded that the negative effect of the introduced hydroxyl groups plays a major role in the NO electrooxidation.

Figure 3 shows the Nyquist plots of various SWCNTs modified electrodes in the PBS saturated with NO. The constant potential is controlled at $0.70 \mathrm{~V}$. The equivalent circuit compatible with the studied system is depicted in the inset. Here, $R_{\mathrm{s}}$ is the solution resistance, constant phase element (CPE) corresponds to the double-layer capacitance, and $R_{\mathrm{ct}}$ is the charge transfer resistance.

It can be seen that there is a big capacitive semicircle at the GC electrode. The capacitive semicircle of the SWCNT-OH modified electrode is smaller than that of the GC electrode, but larger than that of the SWCNTs modified electrode. The SWCNT$\mathrm{COOH}$ modified electrode has the smallest capacitive semicircle. The resistance values of charge transfer can be calculated by Zview2 software from the above capacitive semicircles. The $R_{\mathrm{ct}}$ value of the GC (figure 3a) electrode is about $1762 \Omega$, it is the highest; the $R_{\text {ct }}$ value of the SWCNT-COOH (figure 3d) modified electrode is about $122 \Omega$, which is the smallest one among them, others, the $R_{\mathrm{ct}}$ values of the SWCNTs (figure $3 b$ ) and the SWCNT$\mathrm{OH}$ (figure 3c) modified electrodes are about $204 \Omega$, $290 \Omega$, respectively. The results match with those of

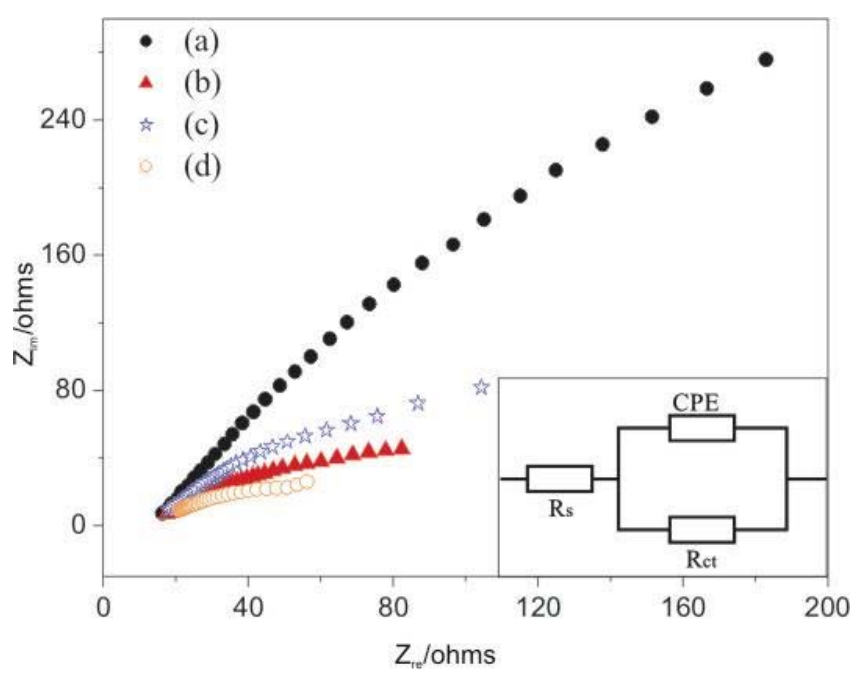

Figure 3. Nyquist plots of various electrodes in the PBS saturated with NO at $0.70 \mathrm{~V}$. The inset is the equivalent circuits compatible with the studied system (a) GC, (b) SWCNTs, (c) SWCNT-OH, (d) SWCNT-COOH. 
the cyclic voltammograms in figure 2. Compared with pure SWCNTs and SWCNT-OH, the SWCNT$\mathrm{COOH}$ which has lowest charge transfer resistance is an excellent electrode material for NO electrooxidation.

\subsection{EIS tests of NO electro-oxidation at SWCNT-COOH modified electrode}

Figure 4a shows the Nyquist plots of the SWCNT$\mathrm{COOH}$ modified electrode in the PBS saturated with $\mathrm{NO}$ and the potential range from 0.35 to $0.64 \mathrm{~V}$. Many incomplete capacitive semicircles appear in the impedance spectra. The capacitive loop deviate away the vertical axis gradually with the increase of potential. When the potential reaches $0.58 \mathrm{~V}$, the capacitive semicircle has a sharp decrease which indicates that the reaction rate of NO electro-oxidation increase significantly. This potential $(0.58 \mathrm{~V})$ just corresponds to the first oxidation peak potential in the cyclic voltammogram (figure $2 \mathrm{~d}$ ).

In figure $4 \mathrm{a}$, the diameter of the capacitive semicircle which represents the resistance of charge transfer decreases when the electrode potential increases from 0.35 to $0.64 \mathrm{~V}$. It means that the NO electro-oxidation reaction in the potential region of the first oxidation peak is driven by the electrode potential. And we can conclude that the reaction rate of NO electro-oxidation in the potential region is controlled by the charge transfer step.

Figure $4 \mathrm{~b}$ shows the Nyquist plots of the SWCNT-COOH modified electrode in the PBS saturated with NO in the potential range of 0.66$0.70 \mathrm{~V}$. The impedance spectra in the potential region show two features: a capacitive semicircle at high frequency and a typical Warburg impedance line at low frequency. The capacitive semicircle represents the charge transfer and the Warburg impedance represents the mass transfer of diffusion. So the reaction rate of $\mathrm{NO}$ electro-oxidation in the potential range of $0.66-0.70 \mathrm{~V}$ is under the control of both the charge transfer and mass transfer of diffusion.

Figure $4 \mathrm{c}$ shows the Nyquist plots of the SWCNT-COOH modified electrode in the PBS saturated with NO in the potential range of 0.72 $0.80 \mathrm{~V}$. It shows that the diameter of capacitive semicircle increases with the electrode potential increasing. But the line length of the Warburg impedance also increases with the electrode potential increasing, this indicates that mass transfer of diffusion becomes dominant in the NO electrooxidation reaction. We explain the increase of the charge transfer resistance in the potential range of $0.72-0.80 \mathrm{~V}$ as follows. The reaction products occupy the active sites on the electrode surface and
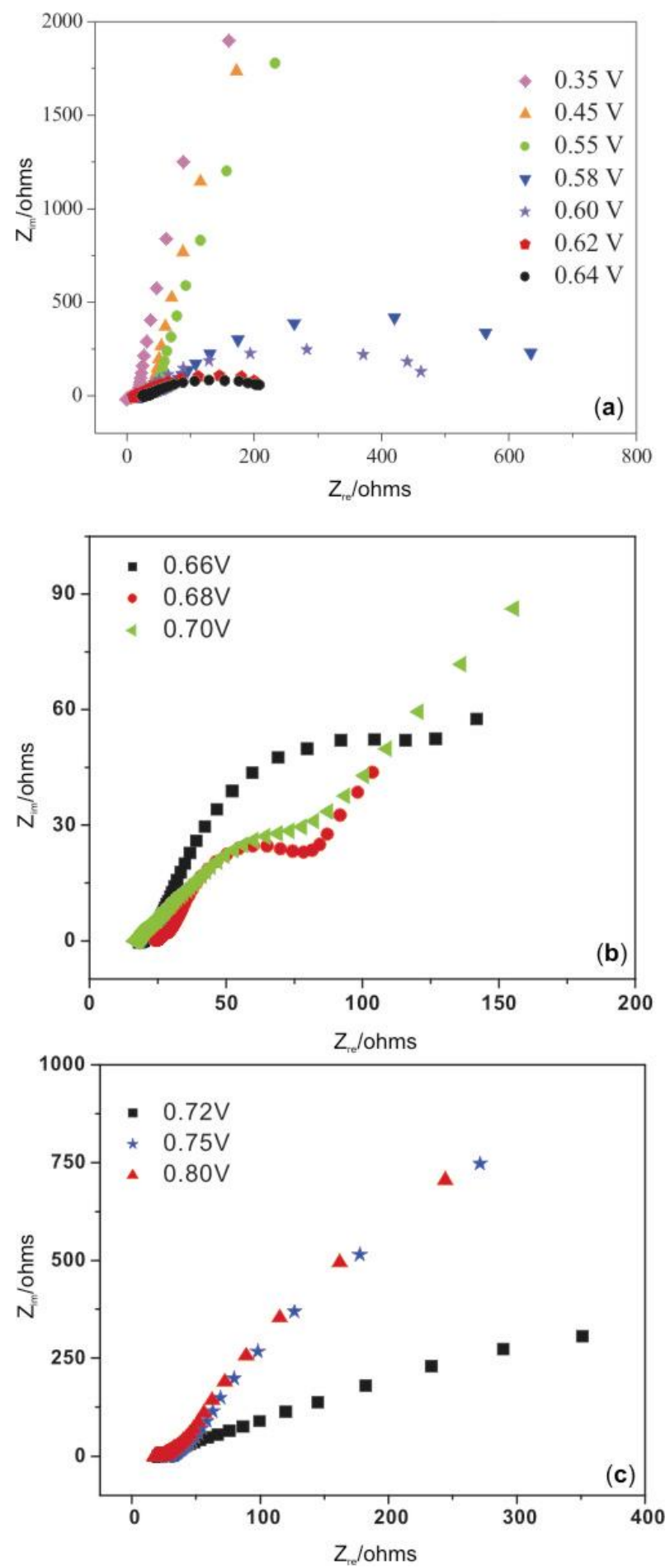

Figure 4. Nyquist plots of the SWCNT-COOH modified electrode in the PBS saturated with $\mathrm{NO}$ at different applied potentials, (a) $0.35-0.64 \mathrm{~V}$; (b) $0.66-0.70 \mathrm{~V}$; (c) $0 \cdot 72-0 \cdot 80 \mathrm{~V}$. 
the desorption rate of the products is low. If the products on the electrode surface can not be desorbed in time, the electron exchange of reactants or intermediates would become difficult. That is so-called 'pollution' or 'poisoning' phenomenon of the electrode surface.

Figure 5 shows the Bode plots of NO electrooxidation at the SWCNT-COOH modified electrode at different applied potentials. The reaction information of the NO electro-oxidation can be obtained from the change of the phase angle with electrode potential. In figure 5, only one maximum phase angle which corresponds to a characteristic frequency $\left(f_{1}\right)$ can be found in each curve. This means that there is only one time constant in all electrochemical reaction processes. When the electrode potential range from 0.58 to $0.66 \mathrm{~V}$ (figure $5 \mathrm{a}$ ), the
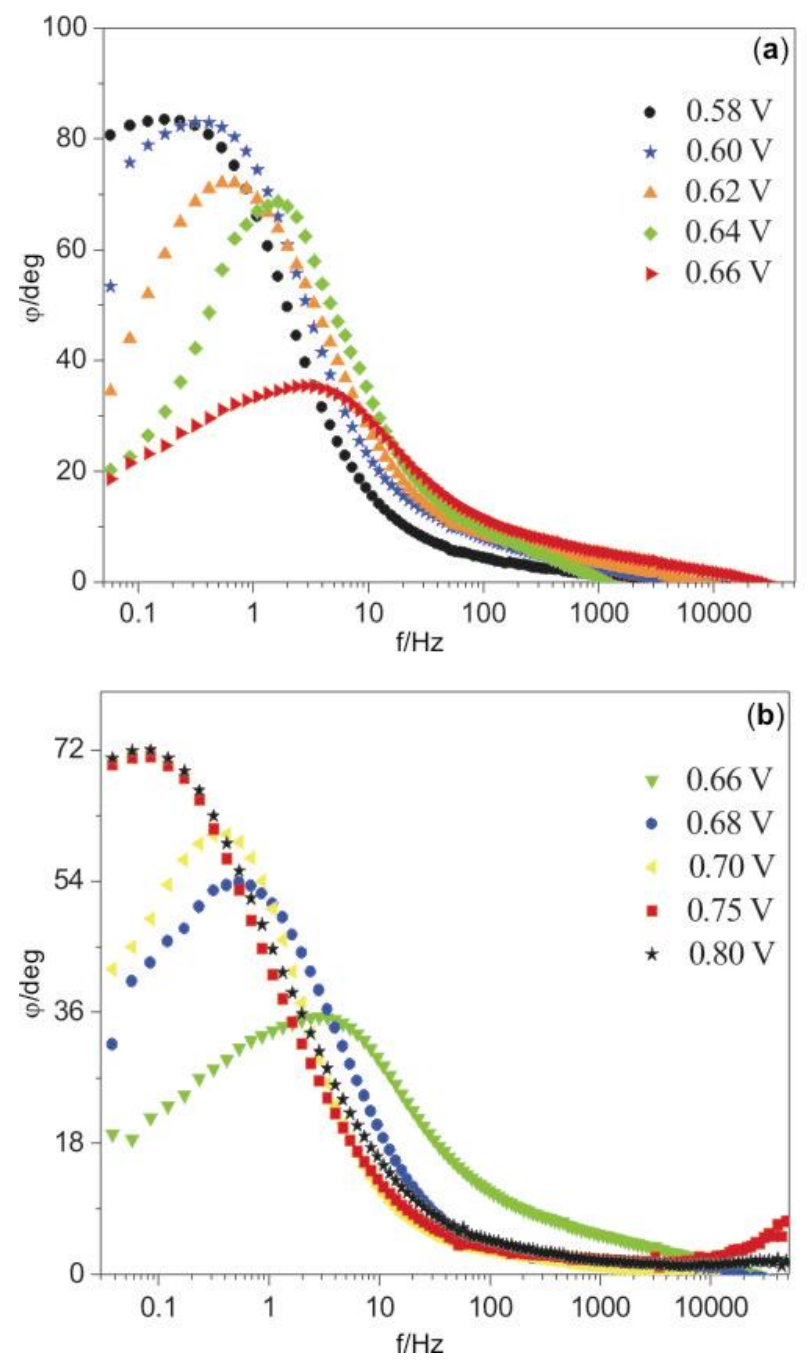

Figure 5. Bode plots of the SWCNT-COOH modified electrode in the PBS saturated with NO at different applied potentials. (a) $0.58-0.66 \mathrm{~V}$, (b) $0.66-0.80 \mathrm{~V}$. characteristic frequency $f_{1}$ has a positive shift toward high frequency with the increase of electrode potential. This indicates that with the increase of the electrode potential, the resistance of charge transfer decreases and the charge transfer rate increases. When the electrode potential is higher than $0.66 \mathrm{~V}$ (figure $5 \mathrm{~b}$ ), the characteristic frequency $f_{1}$ of the maximum phase angle has a negative shift toward low frequency. The charge transfer rate decreases with the increase of electrode potential because the active sites on the electrode surface are occupied by products. In both figures $5 \mathrm{a}$ and $\mathrm{b}$, there is no negative phase angle. So it can be concluded that there is no strong absorption of reactants and intermediates in the electrode surface.

It is noteworthy that the results of the EIS do not match with the results of $\mathrm{CV}$ under the electrode potential from 0.67 to $0.82 \mathrm{~V}$. The current density keeps on increasing with the increase of electrode potential from $0.67 \mathrm{~V}$ to the second oxidation peak potential $(0.82 \mathrm{~V})$ in cyclic voltammogram of figure $2 \mathrm{~d}$, in other words, the reaction rate of NO electrooxidation increase. But as shown in the EIS (figures $4 \mathrm{~b}$ and $\mathrm{c}$ ), the reaction rate decreases with the increasing of electrode potential from 0.67 to $0.82 \mathrm{~V}$ according to the impedance change. This phenomenon may attribute to the poisoning of the electrode and the holdback of the NO diffusion to the electrode. The CV measurement is carried out under increasing potential from low to high and for several minutes. While in EIS measurement under the high potential from 0.67 to $0.82 \mathrm{~V}$, the potential is set to a constant value for about $30 \mathrm{~min}$ and the reaction on the electrode surface is very fast. So the reaction products occupy the electrode surface to poison the electrode in EIS. At the same time, the reaction products on the electrode surface block the diffusion of NO and impede the NO electro-oxidation.

\subsection{Mechanism of NO electro-oxidation reaction}

The curve (c) in figure 6 shows the cyclic voltammogram at SWCNT-COOH modified electrode in the PBS containing $0.02 \mathrm{~mol} \mathrm{~L}^{-1} \mathrm{NaNO}_{2}$ (without $\mathrm{NO}$ gas). It can be seen that there is only one oxidative peak which starts from $0.65 \mathrm{~V}$ and reach to $0.78 \mathrm{~V}$. Compared with the two curves in figures $6 \mathrm{a}$ and $\mathrm{c}$, it can be inferred that the anodic oxidation peak of $\mathrm{NO}_{2}^{-}$is completely contained in the second peak at the SWCNT-COOH modified electrode and the peak current density increases with the increas- 
ing concentration of the $\mathrm{NaNO}_{2}$ (see figure 6d). In order to confirm this, $\mathrm{NaNO}_{3}$ is added into the PBS without $\mathrm{NO}$ and results show that there is no oxidation peak in figure $6 \mathrm{~b}$, This indicates that the $\mathrm{NO}_{3}^{-}$is the only product and can not be oxidized further. That means the second peak in the cyclic voltammogram of NO electro-oxidation at the SWCNT$\mathrm{COOH}$ modified electrode is mainly attributed to the oxidation of $\mathrm{NO}_{2}^{-}$. The potential regions in figures $4 \mathrm{~b}$ and $\mathrm{c}$ correspond to the second oxidation peak in cyclic voltammogram of figure $6 \mathrm{a}$, in other words, EIS in this potential regions corresponds to the reaction change from $\mathrm{NO}_{2}^{-}$to product.

$\mathrm{NO}_{2}^{-}$and $\mathrm{NO}_{3}^{-}$concentration of electrolyte solution is detected by Ion Chromatography before and after reaction $\left(\mathrm{NO}_{2}^{-}\right.$and $\mathrm{NO}_{3}^{-}$do not interfere with each other on the determination). It is found that there is only a small amount of $\mathrm{NO}_{2}^{-}$and $\mathrm{NO}_{3}^{-}$in the $\mathrm{NO}$ saturated $\mathrm{PBS}$ before $\mathrm{CV}$ scan. The concentration of $\mathrm{NO}_{2}^{-}$is $2.5 \times 10^{-4} \mathrm{~mol} \mathrm{~L}^{-1}$ and the concentration of $\mathrm{NO}_{3}^{-}$is $0.2 \times 10^{-4} \mathrm{~mol} \mathrm{~L}^{-1}$ respectively. However, the concentration of $\mathrm{NO}_{2}^{-}$and $\mathrm{NO}_{3}^{-}$increases obviously after NO electro-oxidation. The concentration of $\mathrm{NO}_{3}^{-}$is $2.1 \times 10^{-3} \mathrm{~mol} \mathrm{~L}^{-1}$ and the concentration of $\mathrm{NO}_{3}^{-}$is $9.7 \times 10^{-3} \mathrm{~mol} \mathrm{~L}^{-1}$ respectively. The results show that both $\mathrm{NO}_{2}^{-}$and $\mathrm{NO}_{3}^{-}$are generated during the NO electro-oxidation process. According to the results of figure $6, \mathrm{NO}_{2}^{-}$is the intermediate and $\mathrm{NO}_{3}^{-}$ is the only product. The overall oxidation reaction of

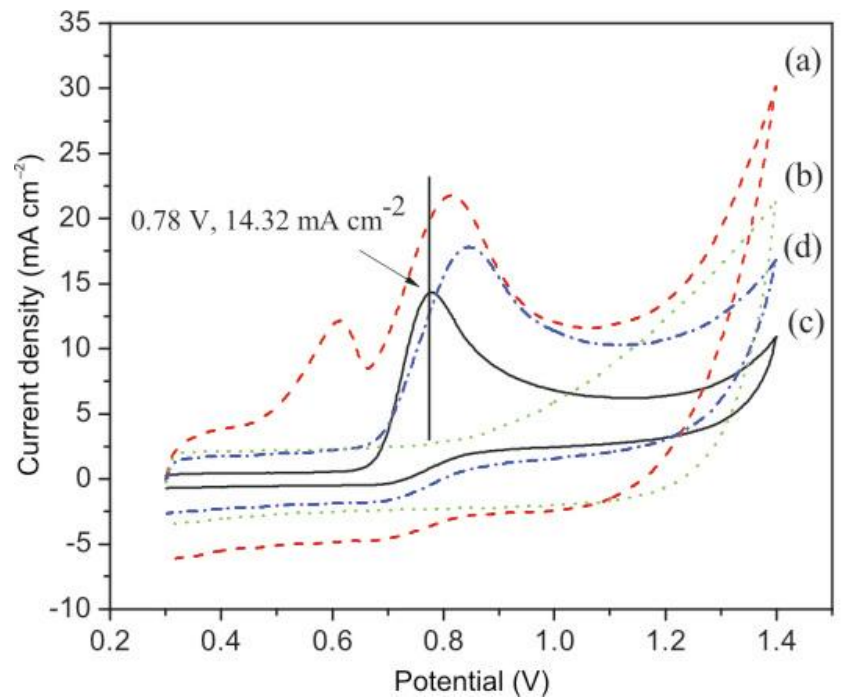

Figure 6. Cyclic voltammograms at the SWCNT$\mathrm{COOH}$ modified electrode in PBS. (a) The PBS saturated with NO; (b) The PBS of $0.02 \mathrm{~mol} \mathrm{~L}^{-1} \mathrm{NaNO}_{3}$ without $\mathrm{NO}$; (c) The PBS of $0.02 \mathrm{~mol} \mathrm{~L}^{-1} \mathrm{NaNO}_{2}$ without $\mathrm{NO}$; (d) The PBS of $0.03 \mathrm{~mol} \mathrm{~L}^{-1} \mathrm{NaNO}_{2}$ without NO. The scan rate was $50 \mathrm{mV} \mathrm{s}^{-1}$.
NO (as shown in scheme 1) is summed up in the equation $^{45,46}: \mathrm{NO}+2 \mathrm{OH}^{-} \rightarrow \mathrm{HNO}_{3}+\mathrm{H}^{+}+3 \mathrm{e}^{-}$.

\section{Conclusions}

Alkali treatment and mixed acids treatment change the surface state of the SWCNTs and hydroxyl groups and carboxyl groups are introduced onto the surface of SWCNTs. The various types of functionalized SWCNTs change electro-catalytic activity to NO electro-oxidation reaction. SWCNT-COOH modified electrode has the best electro-catalytic activity among them.

The reaction equation of $\mathrm{NO}$ electro-oxidation is: $\mathrm{NO}+2 \mathrm{OH}^{-} \rightarrow \mathrm{HNO}_{3}+\mathrm{H}^{+}+3 \mathrm{e}^{-}$. EIS and CV studies indicate that there are three characteristic potential regions and two reaction steps. When the electrode potential is between $0.35 \mathrm{~V}$ and $0.64 \mathrm{~V}$, the electrooxidation process is controlled by charge transfer and the intermediate $\mathrm{NO}_{2}^{-}$emerges in this process. When the electrode potential is higher than

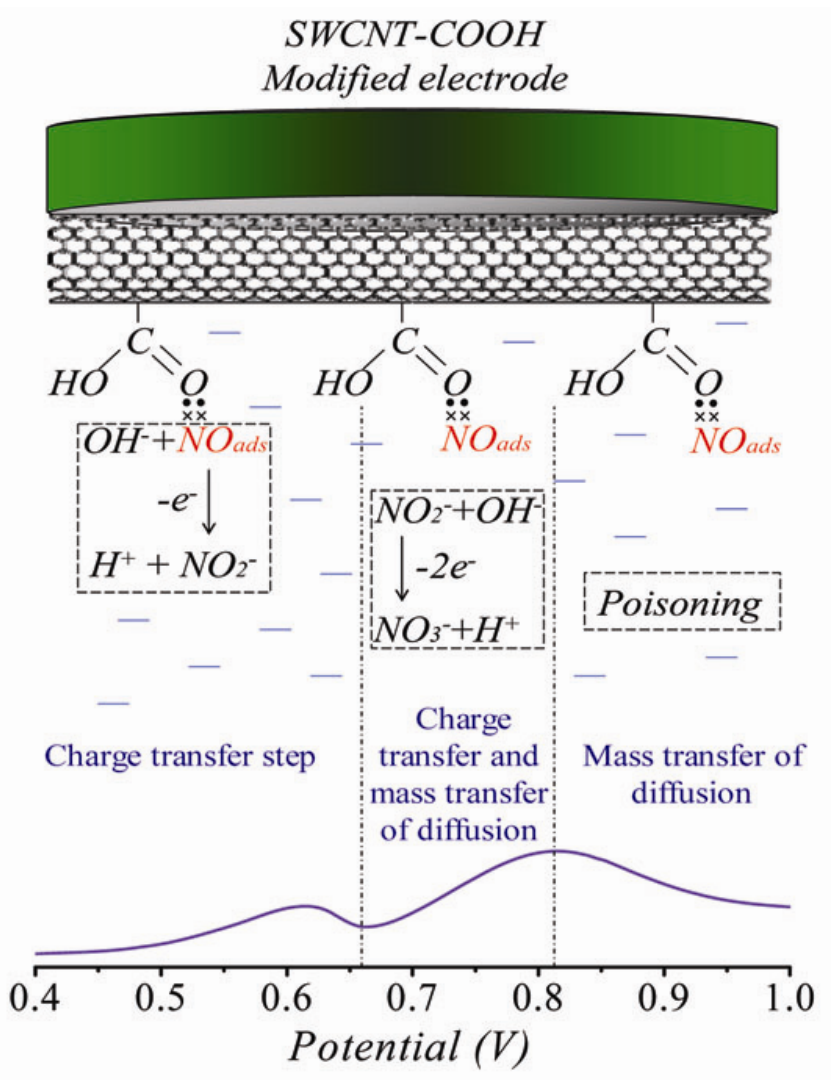

Scheme 1. Diagram of NO electro-oxidation reaction mechanism at the SWCNT-COOH modified electrode. 
$0.66 \mathrm{~V}$, the NO electro-oxidation process is controlled by both charge transfer and mass transfer of diffusion. And $\mathrm{NO}_{3}^{-}$emerges in this potential region. The mass transfer of diffusion becomes dominant gradually with the increase of electrode potential. However, when the electrode potential is higher than $0.72 \mathrm{~V}$, the 'poisoning' phenomenon on the electrode surface occurs due to slow desorption of products. The actual formation mechanism of 'poisoning' phenomenon is a subject for further study.

\section{Acknowledgements}

This work was supported by the Key Program Projects of National Natural Science Foundation of China (No. 20431030) and the National Natural Science Foundation of China (No. 20676027).

\section{References}

1. Terrones M 2004 Int. Mater. Rev. 49325

2. Dyke C A and Tour J M 2004 J. Phys. Chem. A108 11151

3. Baughman R H, Zakhidov A A and de Heer W A 2002 Science 297787

4. Bianco A, Kostarelos K, Partidos C D and Prato M 2005 Chem. Commun. 5571

5. Schenhar R, Norsten T B and Rotello V M $2005 A d v$. Mater. 17657

6. Yoon B and Wai C M 2005 J. Am. Chem. Soc. 127 17174

7. Kong J, Franklin N R, Zhou C, Chapline M G, Peng S, Cho K and Dai H 2000 Science 287622

8. Zhao J, Buldum A, Han J and Lu J P 2002 Nanotechnology 13195

9. Li J, Lu Y, Ye Q, Cinke M, Han J and Meyyappan M 2003 Nano Lett. 3929

10. Lu Y, Li J, Han J, Ng H T, Binder C, Partridge C and Meyyapan M 2004 Chem. Phys. Lett. 391344

11. Quang N H, Trinh M V, Lee B H and Huh J S 2006 Sens. Actuators B113 341

12. Fujiwara A, Ishii K, Suematru H, Kataura H, Maniwa Y, Suzuki S and Achiba Y 2001 Chem. Phys. Lett. 336205

13. Kuznetsova A, Mawhinney D B, Naumenko V, Yates Jr J T, Liu J and Smalley R E 2000 Chem. Phys. Lett. 321292

14. Babaa M R, Dupont N, Pavlovsky E, McRae K and Varlot M 2004 Carbon 421549

15. Shi W and Johnson J K 2003 Phys. Rev. Lett. 91015504

16. Mcneil C J and Manning P 2002 Rev. Mol. Biotech. 82443

17. Taha Z H. 2003 Talanta 613

18. Tarpey M M and Fridovich I 2001 Circ. Res. 89224

19. Lucci M, Reale A, Carlo A D, Orlanducci S, Tamburri E, Terranova M L, Davoli I, Natale C D, Amico A D and Paolesse R 2006 Sens. Actuators B118 226
20. Penza M, Cassano G, Aversa P, Cusano A, Cutolo A, Giordiano M and Nicolais L 2005 Nanotechnology 16 2536

21. Parikh K, Cattanach K, Rao R, Suh D S, Wu A and Manohar S K 2006 Sens. Actuators B113 55

22. Kordás K, Mustonen T, Tóth G, Jantunen H, Lajunen M, Soldano C, Talapatra S, Kar S, Vajtai R and Ajayan P M 2006 Small 21021

23. Jani M, Tero M, Krisztián K, Sami S, Géza T and Jouko V 2007 Phys. Status Solidi B244 4298

24. Lei J P, Ju H X and Ikeda O $2004 \mathrm{~J}$. Electroanal. Chem. $\mathbf{5 6 7} 331$

25. Chang S C, Pereira-Rodrigues N, Henderson J R, Cole A, Bedioui F and McNeil C J 2005 Biosens. Bioelectron. 21917

26. Lee Y, Oh B K and Meyerhoff M E 2004 Anal. Chem. 76536

27. Yu A, Liang Z J, Cho J H and Caruso F 2003 Nano Lett. 31203

28. Wang S Q and Lin X Q 2005 Electrochim. Acta 50 2887

29. Wang Y, Li Q and Hu S 2005 Bioelectrochemistry 65 135

30. Nugent J M, Santhanam K S V, Rubio A and Ajayan P M 2001 Nano Lett. 187

31. Dai X, Wildgoose G G and Compton R G 2006 Analyst 131901

32. Hu C G, Chen X X and Hu S S 2006 J. Electroanal. Chem. $\mathbf{5 8 6} 77$

33. Antiochia R and Lavagnini I 2006 Anal. Lett. 391643

34. Ricci F, Amine A, Moscone D and Palleschi G 2003 Anal. Lett. 361921

35. Yakabson B I and Smally R E 1997 Am. Sci. 85324

36. Yuan H, Guo D, Li X, Yuan L, Zhu W, Chen L and Qiu X 2009 Fuel Cells 9121

37. Qiao J, Tang S N, Tian Y N, Shuang S M, Dong C and Choi M M F 2009 Sensors Actuators B: Chemical 138402

38. Fu D L, Xu Y P, Li L J, Chen Y, Mhaisalkar S G, Boey F Y C, Lin T W and Moochhala S 2007 Carbon 451911

39. Li C M, Zang J F, Zhan D P, Chen W, Sun C Q, Teo A L, Chua Y T, Lee V S and Moochhalac S M 2006 Electroanalysis 18713

40. Chen X J, Lin M, Zhong W B, Chen X H and Chen Z H 2007 Macromol. Chem. Phys. 208964

41. Colthup N B, Daly L H and Wiberlay S E 1990 Introduction to infrared and Raman spectroscopy (Boston: Acadamic Press)

42. Kuznetsova A, Mawhinney D B, Naumenko V, Yates J T J, Liu J and Smalley R E 2000 Chem. Phys. Lett. 321292

43. Lee S M, Lee S C, Jung J H and Kim H J 2005 Chem. Phys. Lett. 416251

44. Jiang Q and Zhao Y 2004 Micropor. Mesopor. Mater. 76215

45. Do J S and Wu K J 2001 J. Appl. Electrochem. 31437

46. De Vooys1 A C A, Beltramo G L, van Riet B, van Veen J A R and Koper M T M 2004 Electrochim. Acta 491307 